\title{
Digestibilidade, cecotrofia, desempenho e rendimento de carcaça de coelhos em crescimento alimentados com rações contendo óleo vegetal ou gordura animal ${ }^{1}$
}

\author{
Vanusa Patrícia de Araújo Ferreira², Walter Motta Ferreira ${ }^{3}$, Eloísa de Oliveira Simões \\ Saliba $^{3}$, Cláudio Scapinello ${ }^{4}$, Alexandre de Oliveira Teixeira ${ }^{5}$, Elis Bernard Kamwa ${ }^{6}$ \\ ${ }_{1}^{1}$ Parte do projeto de tese de Doutorado da primeira autora, financiado pelo CNPq. \\ ${ }^{2}$ FEAD - Minas, Rua Cláudio Manoel, 1162 - Funcionários, Belo Horizonte - MG - CEP: 30140-100. \\ ${ }^{3}$ Escola de Veterinária da Universidade Federal de Minas Gerais (EV/UFMG), Av. Presidente Antônio Carlos, 6627, CEP: 30.161-970. \\ ${ }^{4}$ Departamento de Zootecnia da Universidade Estadual de Maringá (UEM) - Maringá - PR. \\ ${ }^{5}$ Bunge Fertilizantes, Chapecó - PR. \\ ${ }^{6}$ UFPR.
}

RESUMO - Dois experimentos foram conduzidos com o objetivo de avaliar o efeito da inclusão de níveis crescentes $(1,5$; 3,$0 ; 4,5$ e $6,0 \%$ ) de óleo de soja (OS) ou gordura animal (gordura de porco - GA) nas dietas sobre a digestibilidade aparente dos nutrientes e o desempenho de coelhos em crescimento. No ensaio de digestibilidade, foram utilizados 72 coelhos da raça NZB, distribuídos em um delineamento inteiramente casualizado, com nove tratamentos e oito repetições. A adição de diferentes níveis de OS ou GA às dietas não influenciou os coeficientes de digestibilidade de MS, MO, PB e EB e a ingestão de MS, mas provocou efeito positivo sobre a digestibilidade do EE e da FDN. Não foi observado efeito da inclusão de OS ou GA sobre a contribuição nutritiva de cecotrofos ou sobre a MS e PB, mas a inclusão de 3 e $6 \%$ de GA aumentou a contribuição nutritiva do EE. No experimento de desempenho, foram utilizados 45 coelhos NZB distribuídos em um delineamento inteiramente casualizado, com nove tratamentos e cinco repetições. Os animais foram alojados logo após o desmame em gaiolas individuais, onde foram controlados o consumo de ração e o ganho de peso até os 77 dias de idade. Os tratamentos não afetaram significativamente o peso final, o ganho de peso diário, a conversão alimentar, os pesos de carcaça, pele, rins e intestino, mas influenciaram negativamente o consumo médio diário e os pesos de fígado e coração.

Palavras-chave: gordura animal, órgãos digestivos, óleo de soja

\section{Effects of feeding increasing levels of vegetable oil or animal fat on digestibility, cecotrophy, performance and carcass yield of growing rabbits}

\begin{abstract}
Two assays were conducted to evaluate the effects of feeding increasing dietary levels (1.5, 3.0, 4.5, and $6 \%$ ) of soybean oil (SO) or animal fat (pork lard - AF) on nutrient apparent digestibility and performance for growing rabbits. In the digestibility assay, 72 NZB rabbits were assigned to a completely randomized design with nine treatments and eight replicates. No treatment effect on the coefficients of digestibility of DM, OM, CP GE or the DM ingestion was observed, however it was observed positive effect on EE and NDF digestibilities. No effect of increasing dietary levels of $\mathrm{SO}$ or $\mathrm{AF}$ on cecotrophe nutritional contribution or DM and $\mathrm{CP}$ was observed, but the addition of 3 and $6 \% \mathrm{AF}$ increased EE nutritional contribution. In the performance assay, 45 rabbits NZB were assigned to a completely randomized design with nine treatments and five replicates. The animals were individually caged immediately after weaning, where feed intake and weight gain were controlled up to 77 days old. No significant treatment effect on final weight, daily weight gain, feed: gain ratio and weights of carcass, leather, kidneys or intestine was observed. It was observed negative effect on daily feed intake and weights of liver and heart.
\end{abstract}

Key Words: animal fat, digestive organs, soybean oil

\section{Introdução}

Vários estudos têm demonstrado claramente que a energia contida na dieta é o fator mais significativo no controle do consumo em coelhos (Lebas, 1989). Os coelhos tentam ajustar seu consumo voluntário de ali- mento em resposta à concentração energética da ração, interferindo diretamente no desempenho do animal tanto na fase de crescimento como na de reprodução (Pascual et al., 1999; Fortun-Lamothe, 1997; Pérez et al., 1996; Xiccato, 1996; Xiccato et al., 1995; Fernandez et al., 1994). 
Considerando os níveis elevados de fibra normalmente utilizados nas dietas para coelhos, pode-se afirmar que as concentrações energéticas dessas dietas são muito baixas (De Blas et al., 1999). Um recurso para elevar o nível energético da dieta é a adição de gorduras ou óleos, que, em virtude de suas propriedades, apresentam também importante papel no fornecimento de ácidos graxos essenciais, no suprimento e na absorção de vitaminas lipossolúveis, possibilitando manter níveis aceitáveis na porcentagem de fibra indigestível e na diminuição da pulverulência da ração durante e após seu processo de fabricação. Seu efeito lubrificante reduz ainda os gastos com manutenção de máquinas e, em determinados níveis, incrementa a qualidade do grânulo (pélete) e melhora a palatabilidade da ração. Além dessas propriedades, Manzano et al. (1995) afirmaram também que as gorduras promovem economia de calorias, em virtude da menor perda no processo de digestão e no metabolismo, resultando em maior disponibilidade energética aos processos produtivos.

Por outro lado, um aumento indiscriminado na concentração de energia da dieta pode resultar em mudanças marcantes no consumo de ração, na conversão alimentar, na composição da carcaça e na qualidade do pélete produzido (Maertens, 1998).

De modo geral, pode-se adicionar em torno de $5 \%$ de óleo vegetal ou GA às rações de animais não-ruminantes. No entanto, a eficácia de sua utilização depende da natureza química e da digestibilidade, que são afetadas por características e interações físico-químicas, pelo comprimento e pelo grau de saturação da cadeia de ácidos graxos (Fernández-Carmona et al., 2000).

A inclusão de gordura em dietas para coelhos em crescimento parece ter efeito positivo sobre os resultados zootécnicos, favorecendo o ganho de peso e melhorando o consumo de alimento. Entretanto, é possível que estes efeitos variem com o tipo de gordura utilizado, visto que alguns resultados em outras espécies indicam diferenças conforme a natureza dos lipídios incorporados. O uso de gordura animal ou de óleo vegetal não parece ter efeito representativo durante o crescimento. Embora em alguns estudos, tenham sido observados altos ganhos de peso, as conclusões não são exclusivamente atribuídas ao nível de lipídios. Em outros trabalhos, altos e baixos consumos de ração resultaram, respectivamente, em maior e menor crescimento quando comparados à dieta controle (Chaabane et al., 1997; Falcão \& Cunha et al., 1996).

Normalmente, as gorduras utilizadas na alimentação de coelhos são o sebo de boi, a gordura de porco e a gordura de aves. Todavia, vários experimentos têm sido realizados utilizando-se óleos, provavelmente em virtude de sua maior padronização e acessibilidade e melhor utilização em comparação às gorduras (Cheeke, 1995).

Não há evidências de que coelhos toleram ou aceitam melhor óleos em relação às gorduras (Santomá et al., 1993; Fernandez \& Fraga, 1996; Cervera et al., 1997). Entretanto, o uso de alguns subprodutos da indústria refinadora de óleo, como as oleínas, tem promovido redução no consumo de alimento (Fernandez \& Fraga, 1996). Cheeke (1995) observou melhoria nos índices de conversão alimentar e no ganho de peso diário com a adição de gordura, mas outros autores constataram melhora na conversão alimentar e nenhum efeito negativo sobre o ganho de peso com adição de gordura à dieta.

Desta forma, o conhecimento aprofundado do valor nutricional de óleos vegetais e de gorduras animais e sua utilização digestiva por coelhos é fundamental para a suplementação alimentar nesta espécie.

Objetivou-se com este trabalho avaliar o efeito da inclusão de diferentes níveis de óleo de soja e gordura animal em dietas para coelhos em crescimento sobre os coeficientes de digestibilidade aparente dos nutrientes, a contribuição nutritiva dos cecotrofos e o desempenho dos animais.

\section{Material e Métodos}

O experimento foi realizado nas dependências do Departamento de Zootecnia da Escola de Veterinária da Universidade Federal de Minas Gerais (UFMG), em Belo Horizonte, Minas Gerais.

Para determinação da digestibilidade fecal aparente dos nutrientes das dietas experimentais, foram utilizados 72 coelhos da raça Nova Zelândia Branco (NZB), com 49 dias de idade $(1,0 \pm 0,10 \mathrm{~kg}$ PV) e desmamados aos 35 dias de idade, distribuídos em um delineamento inteiramente casualizado, em esquema fatorial, com duas fontes de gordura (óleo de soja e gordura animal), quatro níveis $(1,5 ; 3,0 ; 4,5$ e $6,0 \%)$ e uma dieta-referência, com oito repetições.

Os animais, metade macho e metade fêmeas, foram alojados individualmente, ao acaso, em gaiolas para estudos de metabolismo equipadas com bebedouro automático (tipo chupeta) e comedouro semi-automático dividido ao meio por um separador para impedir o desperdício de ração (fornecida à vontade). Na parte superior das bandejas de coleta, foram adaptadas telas de náilon para retenção das fezes. As gaiolas foram instaladas em ambiente controlado com temperatura entre 18 e $22^{\circ} \mathrm{C}$.

Os tratamentos constaram de dietas experimentais (Tabela 1) formuladas para atender às exigências nutricionais 
de coelhos em crescimento, conforme descrito por de De Blas \& Mateos (1998), adicionadas de níveis crescentes $(1,5 ; 3,0 ; 4,5$ e $6,0 \%)$ de óleo de soja (OS) ou de níveis crescentes $(1,5 ; 3,0 ; 4,5$ e $6,0 \%)$ de gordura animal (GA gordura de porco) e de uma dieta-referência (DR), sem a adição de óleo de soja ou gordura animal. Todos os ingredientes utilizados possuíam granulometria de $\pm 0,6 \mathrm{~mm}$ e foram peletizados (péletes de 12 a $15 \mathrm{~mm}$ de comprimento por 4 a $5 \mathrm{~mm}$ de diâmetro) em peletizadora de pressão sem injeção de vapor.

Tabela 1 - Composição das dietas experimentais

Table 1 - Ingredient composition of the experimentals diets

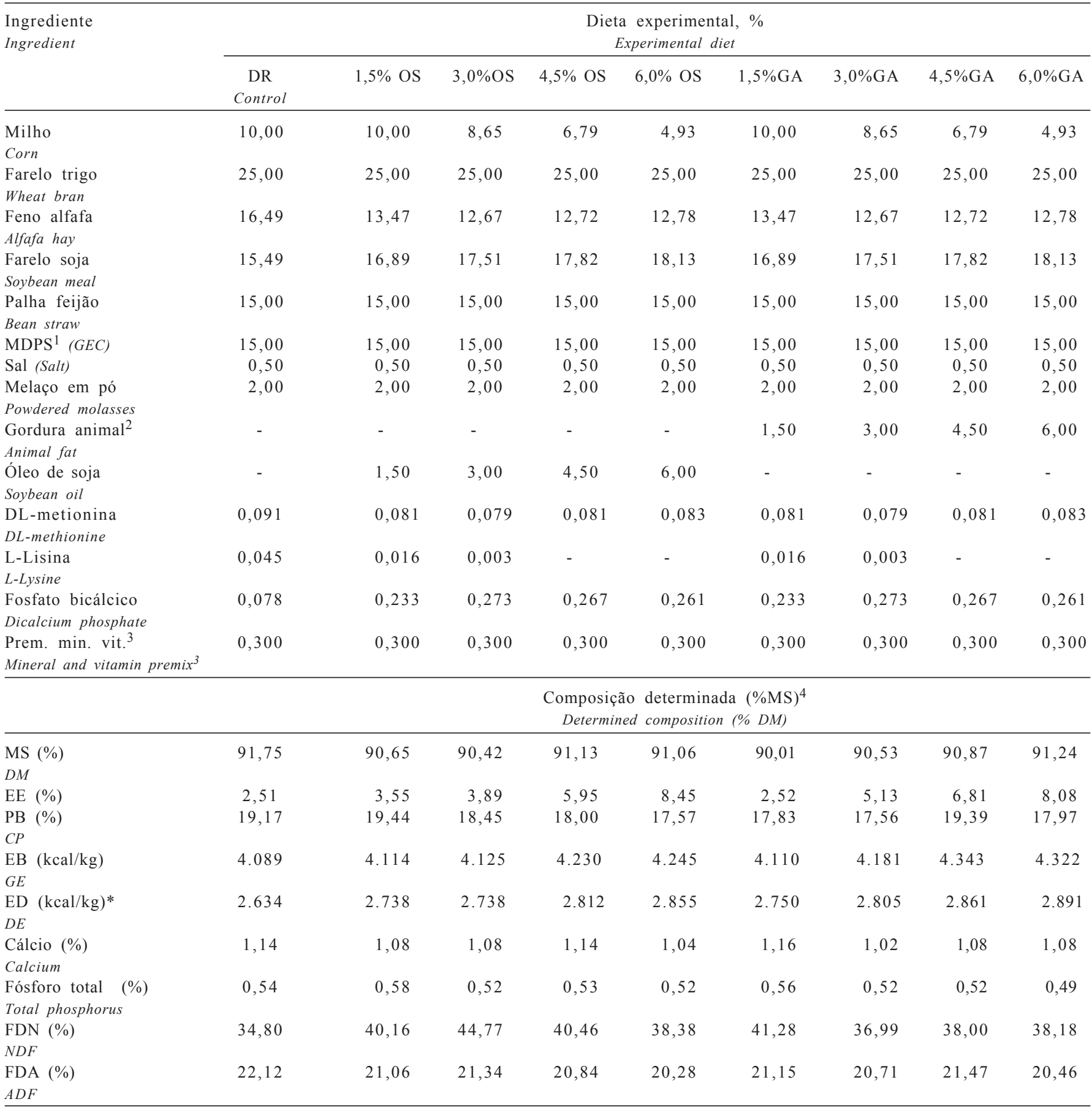

${ }^{1}$ MDPS - Milho desintegrado com palha e sabugo (GEC = ground ear corn).

2 Gordura de porco (pig fat).

3 Composição do premix mineral/vitamínico (Composition of mineral and vitamin premix): Se - 0,10 mg; I - 0,40 mg; Cu - 10 mg; Mg - 40mg; Zn - 50 mg; Co 1,0 mg; Vit. A - 10,000 UI; Vit. D3 - 1,000 UI; Vit. E - 15 mg; Vit. B12 - 10 mg; Vit. K3 - 2 mg; Tiamina (Tiamine) - 2 mg; Riboflavina (Riboflavine) - 5 mg; Piridoxina (Piridoxine) - 3 mg; Niacina (Niacin) - 30 mg; Ácido pantotênico (Pantothenic acid) - 15 mg; Colina (Choline) - 500 mg; Ácido fólico (Folic acid).

${ }^{*} \mathrm{ED}(\mathrm{kcal} / \mathrm{kg})=\mathrm{EB}(\mathrm{kcal} / \mathrm{kg} \mathrm{MS})$ * $\underline{(84,77-1,16 * \text { FDA\%MS}) \quad(D e ~ B l a s ~ e t ~ a l ., ~ 1989) . ~}$ 
O experimento consistiu de um período de sete dias de adaptação às condições experimentais e mais quatro para coleta total de fezes e controle do consumo. Os animais foram pesados no início e ao final do período experimental, efetuando-se a coleta de amostras das dietas. Os procedimentos de campo, de preparo das amostras de fezes e alimentos e os cálculos dos valores de digestibilidade utilizados foram descritos por Perez et al. (1995), Xiccato et al. (1996) e EGRAN (1999).

As fezes foram colhidas diariamente de cada repetição e acondicionadas em sacos plásticos devidamente identificados, os quais foram fechados e armazenados em freezer $\left(-18^{\circ} \mathrm{C}\right)$ para posteriores análises químicas. Após o período de coleta, as amostras foram descongeladas em temperatura ambiente (aproximadamente 12 horas), sendo homogeneizadas, colocadas em bandejas de alumínio, pesadas em balança analítica e mantidas em estufa de ventilação forçada a $65^{\circ} \mathrm{C}$, por 72 horas. Depois de retiradas da estufa, atingindo o equilíbrio com a temperatura ambiente, as amostras de fezes duras foram submetidas às análises químicas com prévia hidrólise ácida, para determinação dos teores de MS, cinzas, $\mathrm{PB}, \mathrm{MO}, \mathrm{FDN}, \mathrm{EB}$ e EE, de acordo com metodologia descrita por Silva (1990).

Após as análises químicas, foram calculados os coeficientes de digestibilidade aparente de MS (CDMS), MO (CDMO), PB (CDPB), FDN (CDFDN) e EB (CDEB), de acordo com a fórmula de Schneider \& Flatt (1975).

Ao final do ensaio de digestibilidade aparente, foi avaliada a produção de cecotrofos durante 24 horas, no intuito de se conhecer a produção total de cecotrofos (fezes moles) e sua contribuição nutricional para o animal alimentado com as diferentes dietas estudadas. Com o objetivo de se evitar a cecotrofia, cada animal recebeu um colar circular de madeira leve, medindo $25 \mathrm{~cm}$ de diâmetro, com um orifício central de $7 \mathrm{~cm}$ de diâmetro. Durante esse período, o consumo de ração foi controlado e os cecotrofos coletados de 4 em 4 horas.

Os cecotrofos de cada animal correspondentes ao período de coleta foram acondicionados em sacos plásticos hermeticamente fechados e congelados a $-18^{\circ} \mathrm{C}$ para posterior determinação das concentrações de MS, PB, cinzas e $\mathrm{EE}$, de acordo com os métodos descritos pelo AOAC (1990) e com os critérios estabelecidos pelo EGRAN (1999). Após o armazenamento, os cecotrofos foram descongelados à temperatura ambiente e homogeneizados. Uma alíquota de $55 \%$ das amostras diárias foi mantida em estufa de ventilação forçada a $65^{\circ} \mathrm{C}$ durante 72 horas e, em seguida, foi conservada em estufa, permanecendo à temperatura e umidade ambiente durante 2 horas para pesagem e determinação da matéria pré-seca. Seqüencialmente, foi processada em moinho Thomas Willey com peneira de 1,0 mm e os pêlos removidos. O material foi armazenado em frascos para posterior análise dos teores de MS, PB e EE, com prévia hidrólise ácida.

A partir dos valores de composição química dos cecotrofos e da respectiva quantidade diária produzida, foi calculado o valor de contribuição de cada princípio nutritivo (MS, PB e EE) em relação ao consumo médio de ração desses mesmos princípios nutritivos em cada uma das nove dietas experimentais, utilizando-se as seguintes fórmulas (Carabaño et al., 1989).

$$
\mathrm{CCMS} \%=\frac{\mathrm{A} \times 100}{\mathrm{~A}+\mathrm{B}} \mathrm{CCPB} \%=\frac{\mathrm{C} \times 100}{\mathrm{C}+\mathrm{D}} \quad \mathrm{CCEE}=\frac{\mathrm{E} \times 100}{\mathrm{E}+\mathrm{F}}
$$

em que: $\mathrm{CCMS}=$ contribuição nutritiva dos cecotrofos em $\mathrm{MS} ; \mathrm{CCPB}=$ contribuição nutritiva dos cecotrofos em PB; CCEE = contribuição nutritiva dos cecotrofos em EE; $\mathrm{A}=$ excreção de fezes moles (gMS/dia); $\mathrm{B}=$ média de ingestão de alimentos durante o período pré-experimental (gMS/dia); C = PB excretada nas fezes moles (g/dia); $\mathrm{D}=\mathrm{PB}$ ingerida no alimento $(\mathrm{g} / \mathrm{dia}) ; \mathrm{E}=\mathrm{EE}$ excretado nas fezes moles ( $\mathrm{g} / \mathrm{dia}) ; \mathrm{F}=\mathrm{EE}$ ingerido no alimento ( $\mathrm{g} / \mathrm{dia}$ ).

O ensaio de desempenho foi conduzido nas instalações do Setor de Cunicultura da Fazenda Experimental Prof. Hélio Barbosa, da Escola de Veterinária da Universidade Federal de Minas Gerais (UFMG).

Foram utilizados 45 coelhos da raça Nova Zelândia Branco (cinco animais por tratamento), de ambos os sexos, com 35 dias de idade, alojados em gaiolas individuais de arame galvanizado $(0,60 \times 0,60 \times 0,37 \mathrm{~m})$, dispostas $\mathrm{em}$ galpão de alvenaria semi-aberto, providas de bebedouro e comedouro, permitindo-se livre acesso ao alimento e à água até os 77 dias de idade. Utilizou-se o mesmo esquema experimental apresentado para a digestibilidade aparente, porém com cinco repetições.

Os efeitos dos tratamentos (Tabela 1) foram avaliados sobre o ganho de peso, o consumo de ração e a conversão alimentar desde a desmama ( 35 dias de idade) até o abate (77 dias de idade). Todos os animais foram pesados ao serem alojados nas gaiolas, no início do experimento e a cada semana. Os ganhos médios de peso foram obtidos pela diferença entre os pesos médios ao final de cada período considerado e o peso médio anterior. O consumo de ração foi medido semanalmente por meio da diferença entre a ração fornecida durante o período e as sobras ao final de cada semana. O consumo médio diário foi calculado em seguida.

O desempenho e a mortalidade foram monitorados semanalmente até os 77 dias de idade, quando se procedeu ao abate. Os animais foram abatidos com pancada na base do crânio (Gidenne \& Lebas, 1984), suspensos pelas patas 
posteriores e sangrados por corte da veia jugular. Imediatamente após a retirada da pele, da cabeça, dos membros e da cauda, os animais foram eviscerados. Foram reservados coração, fígado, rins e intestinos da carcaça quente para cálculo de seus respectivos pesos e do rendimento de carcaça.

Os dados experimentais de digestibilidade e desempenho foram submetidos à análise de variância. Utilizou-se o software estatístico SAS ${ }^{\circledR}$ (SAS, 1996), sendo as médias das fontes de gordura comparadas pelo teste SNK e os níveis submetidos à análise de regressão.

$$
Y i j=\mu+\sigma+\beta j+(\sigma \beta) i j+E i j ; i=1,2 j=1,2,3,4
$$

em que $\mathrm{Yij}=$ observação relativa a i-ésima fonte de gordura e j-ésimo nível; $\mu$ = média geral; $\sigma=$ efeito da i-ésima fonte de gordura; $\beta \mathrm{j}=$ efeito do $\mathrm{j}$-ésimo nível. $(\sigma \beta) \mathrm{ij}=$ efeito da interação i-ésima fonte de gordura $\times \mathrm{j}$-ésimo nível; Eij = erro aleatório associado a cada observação, pressuposto independente e normalmente distribuído com média $\mu$ e variância $\sigma^{2}$.

\section{Resultados e Discussão}

Mediante a análise de variância, constatou-se que não houve efeito significativo da interação fontes de energia $\times$ níveis utilizados nas dietas experimentais sobre os CDMS, CDMO, CDPB, CDEB e sobre a ingestão de matéria seca (Tabela 2).

$A$ adição de diferentes níveis de $\mathrm{OS}$ e GA às dietas não influenciou os CDMS, CDMO, CDPB, CDEB e a ingestão de MS. Resultados semelhantes foram encontrados por Moretti (2002), que adicionou $3 \%$ de óleo de soja, canola e milho em dietas para coelhos em crescimento e não observou melhoria em nenhum coeficiente de digestibilidade dos nutrientes das dietas.
De Blas et al. (1995) avaliando a substituição do amido por gordura animal e fibra em dietas isoenergéticas, obtiveram melhores CDFDN, CDEB e CDMS e piores resultados para os coeficientes de digestibilidade do amido e da proteína.

Diversos autores têm demonstrado que o nível de gordura da dieta não afeta a digestibilidade da PB (De Blas et al., 1995; Fernández-Carmona et al., 1998), mas isto pode ser explicado por mudanças na origem da proteína (como a proporção de proteína da forragem), como sugerido por Santomá et al. (1987).

Pelas médias dos CDEE e CDFDN das dietas formuladas com diferentes níveis de OS ou GA (Tabelas 3 e 4), observa-se que houve interação significativa fontes $\times$ níveis de gordura.

O CDEE foi maior $(\mathrm{P}<0,05)$ com o acréscimo de $6,0 \%$ de OS ou GA, como pode ser verificado nas equações de regressão 1 e 2 . A melhora na utilização digestiva dos nutrientes da dieta é mais evidente quando utilizados níveis superiores a 3\% de óleos ou gorduras (Falcão e Cunha et al., 1998; Falcão e Cunha et al., 2000), como observado neste experimento para os CDEE, que foram maiores quando adicionados $6,0 \%$ de OS ou $6,0 \%$ de GA.

As equações de regressão obtidas neste trabalho para a predição da digestibilidade do EE das dietas foram:

$$
\mathrm{Y}=39,49+16,39 \mathrm{x}-1,53 \mathrm{x}^{2} \mathrm{R}^{2}=72,17 \% \text { (Equação } 1 \text { ) }
$$
em que: $\mathrm{Y}=\mathrm{CDEE}_{\text {dieta }} ; \mathrm{X}=$ porcentagem de gordura animal da dieta;

$$
Y=70,58+0,12 x+0,40 x^{2} R^{2}=84,08 \% \text { (Equação 2) }
$$
em que: $\mathrm{Y}=\mathrm{CDEE}_{\text {dieta }} ; \mathrm{X}=$ porcentagem de óleo de soja da dieta.

A partir das regressões de maximização de digestibilidade do EE, observa-se que houve maior digestibilidade quando incluídos $6 \%$ de GA ou de OS nas dietas.

Tabela 2 - Coeficientes de digestibilidade aparente de MS, MO, PB e EB, ingestão de MS das dietas e contribuição nutritiva de cecotrofos em MS (CCMS) e PB (CCPB)

\begin{tabular}{|c|c|c|c|c|c|c|c|c|c|c|c|c|c|}
\hline \multirow[t]{2}{*}{$\begin{array}{l}\text { Nutriente (\%) } \\
\text { Nutrient (\%) }\end{array}$} & \multicolumn{5}{|c|}{$\begin{array}{l}\text { Nível de óleo de soja (\%) } \\
\text { Level of soy oil (\%) }\end{array}$} & \multirow{2}{*}{$\begin{array}{c}\overline{\mathrm{X}} \\
\text { Média } \\
\text { Mean }\end{array}$} & \multicolumn{5}{|c|}{$\begin{array}{c}\text { Nível de gordura animal (\%) } \\
\text { Level of animal fat }(\%)\end{array}$} & \multirow{2}{*}{$\begin{array}{l}\overline{\mathrm{X}} \\
\text { Média } \\
\text { Mean }\end{array}$} & \multirow[t]{2}{*}{ CV (\%) } \\
\hline & 0,0 & 1,5 & 3,0 & 4,5 & 6,0 & & 0,0 & 1,5 & 3,0 & 4,5 & 6,0 & & \\
\hline $\mathrm{MS}(D M)$ & 64,06 & 64,67 & 62,28 & 61,45 & 63,10 & 63,11 & 64,06 & 63,78 & 63,41 & 63,65 & 63,93 & 63,76 & 4,32 \\
\hline $\mathrm{MO}(O M)$ & 64,07 & 64,64 & 62,35 & 61,46 & 63,00 & 63,10 & 64,07 & 63,29 & 62,99 & 63,44 & 63,61 & 63,48 & 4,29 \\
\hline $\mathrm{PB}(C P)$ & 79,80 & 80,22 & 78,25 & 77,14 & 78,39 & 78,76 & 79,80 & 80,31 & 78,45 & 78,77 & 80,19 & 79,50 & 3,81 \\
\hline $\mathrm{EB}(G E)$ & 63,62 & 64,90 & 61,92 & 62,52 & 63,63 & 63,31 & 63,62 & 63,33 & 63,39 & 64,00 & 64,30 & 63,72 & 4,18 \\
\hline $\begin{array}{l}\text { Ingestão de MS } \\
\text { DM intake }\end{array}$ & 336,47 & 361,53 & 332,04 & 378,18 & 363,07 & 354,25 & 336,47 & 338,38 & 327,58 & 333,82 & 329,11 & 333,07 & 18,95 \\
\hline CCMS (CCDM) & 17,65 & 16,74 & 17,92 & 17,49 & 17,13 & 17,38 & 17,65 & 17,11 & 16,53 & 16,46 & 18,89 & 17,32 & 25,10 \\
\hline $\mathrm{CCPB}(C C C P)$ & 28,47 & 28,33 & 27,65 & 27,50 & 27,61 & 27,91 & 28,47 & 27,98 & 27,83 & 27,34 & 27,79 & 27,88 & 18,38 \\
\hline
\end{tabular}

Table 2 - Coefficients of apparent digestibility of $D M, O M, C P$, and $G E$, dietary DM intake and cecotroph nutritive contribution in $D M(C C D M)$ and $C P(C C C P)$ 
Tabela 3 - Coeficientes de digestibilidade aparente do EE das dietas

Table 3 - Coefficients of dietary apparent EE digestibility

\begin{tabular}{|c|c|c|c|c|}
\hline $\begin{array}{l}\text { Nutriente (\%) } \\
\text { Nutrient (\%) }\end{array}$ & & $\begin{array}{l}\text { Nível } \\
\text { Level }\end{array}$ & $\begin{array}{l}\text { a }(\%) \\
\text { et }(\%)\end{array}$ & \\
\hline $\begin{array}{l}\text { Fonte gordura } \\
\text { Fat source }\end{array}$ & 1,5 & 3,0 & 4,5 & 6,0 \\
\hline
\end{tabular}

Coeficiente de digestibilidade aparente Coefficient of apparent digestibility

\begin{tabular}{lllll}
\hline Óleo de soja & $73,80 \mathrm{~A}$ & $73,11 \mathrm{~A}$ & $80,95 \mathrm{~A}$ & $85,14 \mathrm{~A}$ \\
$\begin{array}{l}\text { Soy oil } \\
\text { Gordura animal }\end{array}$ & $59,89 \mathrm{~B}$ & $77,46 \mathrm{~A}$ & $80,03 \mathrm{~A}$ & $83,49 \mathrm{~A}$ \\
\begin{tabular}{l} 
Animal fat \\
\hline
\end{tabular} & & & & \\
\hline
\end{tabular}

$A=$ Médias com letras maiúsculas iguais na mesma coluna não diferem $(P>0,05)$ pelo teste Student Newman Keuls.

$A=$ Means followed by the same capital letters within a column do not differ $(P>0.05)$ by Student Newman Keuls test.

Tabela 4 - Coeficientes de digestibilidade aparente da FDN das dietas

Table 4 - Coefficients of dietary apparent NDF digestibility

\begin{tabular}{lcccc}
\hline & \multicolumn{4}{c}{$\begin{array}{c}\text { Nível na dieta (\%) } \\
\text { Level in the diet (\%) }\end{array}$} \\
\cline { 2 - 5 } $\begin{array}{l}\text { Fonte gordura } \\
\text { Fat source }\end{array}$ & 1,5 & 3,0 & 4,5 & 6,0 \\
\hline \multicolumn{4}{c}{ Coeficiente de digestibilidade aparente } \\
Coefficient of apparent digestibility
\end{tabular}

$A=$ Médias com letras maiúsculas iguais na mesma coluna não diferem $(P>0,05)$ pelo teste Student Newman Keuls.

$A=$ Means followed by the same capital letters within a column do not differ $(P>0.05)$ by Student Newman Keuls test.

De acordo com alguns autores (Cheeke, 1995; Lopes et al., 1997; Xiccato, 1996), o aumento na digestibilidade do EE das dietas com altos níveis de óleo é acompanhado pela redução na ingestão de MS, que normalmente ocorre quando uma dieta altamente energética é oferecida, como conseqüência da regulação quimiostática do apetite. Entretanto, isso não ocorreu neste trabalho, pois não houve efeito da adição de gordura às dietas na ingestão de MS, como conseqüência da preocupação em se manter níveis muito próximos de ED entre as dietas.

Houve efeito (Tabela 4) da adição de diferentes tipos e níveis de gordura $(\mathrm{P}<0,05)$ sobre o $\mathrm{CDFDN}$ quando se utilizou o nível 3\%, observando-se maior e menor digestibilidade para OS e GA, respectivamente. Esta diferença também pôde ser observada para CDEE (Tabela 3), porém no nível 1,5\%. Segundo Maertens (1998), no entanto, não há evidências de que haja diferença entre o uso de gordura animal e óleos vegetais na utilização digestiva dos nutrientes da dieta.

Não houve efeito interação significativa entre os tipos e os níveis de gordura utilizados nas dietas experimentais sobre a CCMS e CCPB (Tabela 2). Também não houve efeito da inclusão de diferentes níveis de OS e GA sobre a CCMS, porém, os valores aproximaram-se dos encontrados por Ferreira (1990), Fraga et al. (1991) e Santiago (2001).

A quantidade ou a fonte de gordura adicionada às dietas não afetou $(\mathrm{P}>0,05)$ a $\mathrm{CCPB}$, mas os valores obtidos aproximaram-se dos observados por Ferreira (1990) e Gomes (1996), que encontraram contribuições dos cecotrofos em relação ao consumo de PB de 28 e $23 \%$, respectivamente.

$\mathrm{Na}$ Tabela 5, nota-se que houve efeito significativo $(\mathrm{P}>0,05)$ do tipo de gordura, pois os níveis de 3,0 e 6,0\% de GA otimizaram $(\mathrm{P}<0,05)$ a CCEE em comparação à inclusão desses mesmos níveis de OS.

A interação níveis $\times$ fontes de gordura não influenciou o desempenho produtivo e o rendimento de carcaça (Tabela 6). A utilização de diferentes níveis de gordura, independentemente das fontes, não alterou $(\mathrm{P}>0,05)$ o peso final, o ganho de peso diário, a conversão alimentar e os pesos de carcaça, pele, rins e intestino. Resultados semelhantes foram encontrados por Falcão e Cunha et al. (2000), que, trabalhando com níveis de 0,0 a 3,5\% de óleo de soja e sebo em dietas para coelhos em crescimento, não encontraram efeito significativo sobre o peso final, o ganho de peso diário e a conversão alimentar.

Houve efeito $(\mathrm{P}<0,05)$ negativo, no entanto, sobre o consumo médio diário e os pesos de fígado e coração. Desta forma, a influência positiva da inclusão da gordura sobre o rendimento de carcaça referido por Raimondi et al. (1974)

Tabela 5 - Contribuição nutritiva dos cecotrofos em EE (CCEE), de acordo com as fontes e os níveis de gordura

Table 5 - Cecotroph nutritive contribuition in EE (CCEE) according of sources and levels of fat

\begin{tabular}{|c|c|c|c|c|}
\hline \multirow{2}{*}{$\begin{array}{l}\text { Nutriente (\%) } \\
\text { Nutrient (\%) } \\
\text { Fonte gordura } \\
\text { Fat source }\end{array}$} & \multicolumn{4}{|c|}{$\begin{array}{l}\text { Nível na dieta (\%) } \\
\text { Level in the diet (\%) }\end{array}$} \\
\hline & 1,5 & 3,0 & 4,5 & 6,0 \\
\hline
\end{tabular}

Contribuição nutritiva dos cecotrofos Cecotroph nutritive contribution

\begin{tabular}{llrrr}
\hline Óleo de soja & $13,65 \mathrm{~A}$ & $8,39 \mathrm{~B}$ & 9,25 & $7,21 \mathrm{~B}$ \\
$\begin{array}{l}\text { Soy oil } \\
\text { Gordura animal }\end{array}$ & $21,83 \mathrm{~A}$ & $27,50 \mathrm{~A}$ & 13,55 & $24,66 \mathrm{~A}$ \\
Animal fat & & & & \\
\hline
\end{tabular}

$\mathrm{A}=$ Médias com letras maiúsculas iguais na mesma coluna não diferem A $(P>0,05)$ pelo teste Student Newman Keuls. $A=$ Means followed by the same capital letters within a column do not differ $(P>0.05)$ by Student Newman Keuls test. 


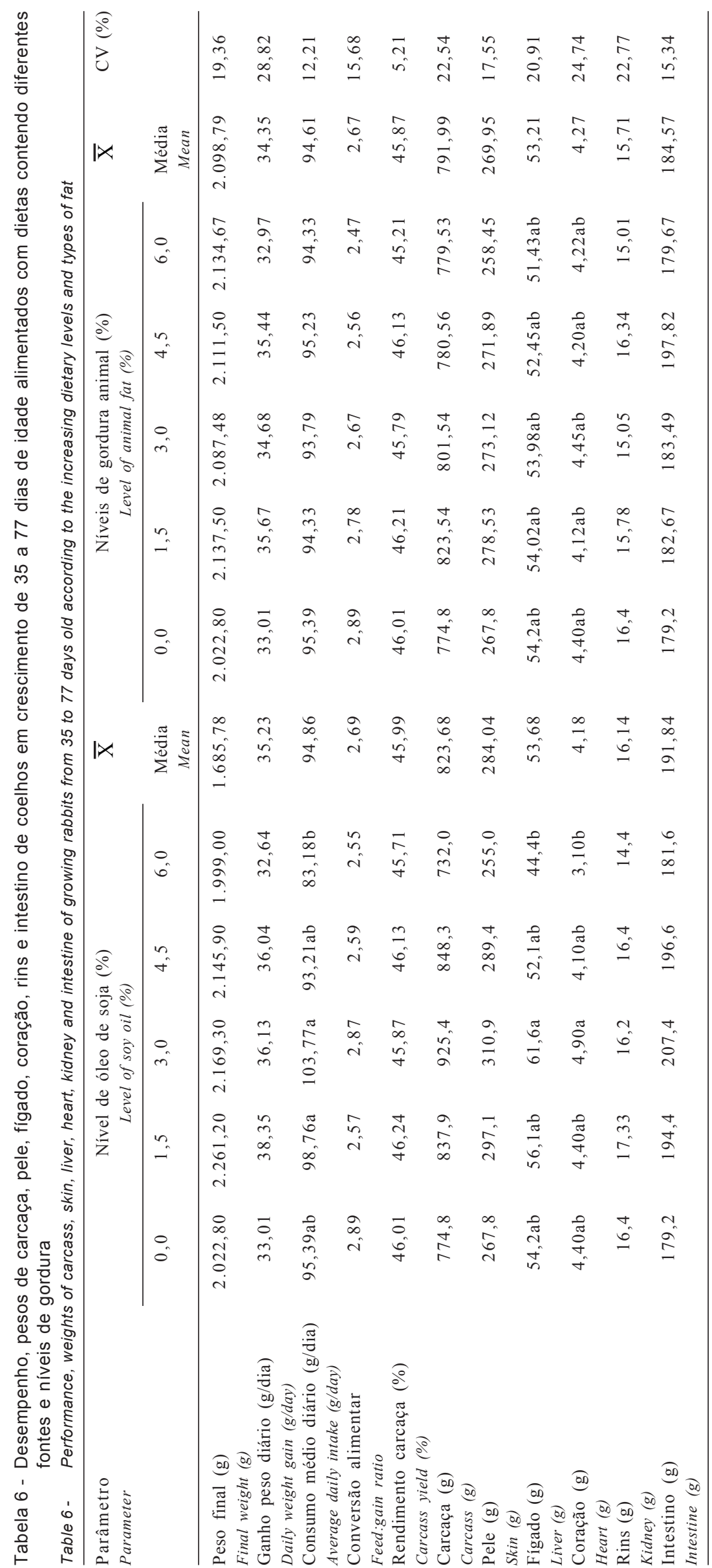


não foi observada neste trabalho. A gordura da carcaça depende, em grande parte, da quantidade de gordura e energia contida na dieta. Quando a adição de gordura resulta em decréscimo da relação energia/proteína, ocorre decréscimo no nível de gordura da carcaça (Fernandez e Fraga, 1996;). Entretanto, segundo (Dalle Zotte et al., 1997; Xiccato et al., 1998), o aumento da gordura na carcaça como efeito residual da gordura adicionada à dieta tem sido observado somente na fase pós-desmama, especialmente no período de 45 a 55 dias de idade.

Os valores de consumo médio diário elevaram com a inclusão de 3,0\% de gordura, mas reduziram significativamente no nível de $6,0 \%$ de gordura. O mesmo ocorreu para os pesos de fígado e coração, provavelmente em razão da proximidade entre os valores de energia digestível nas dietas, visto que o coelho manifesta capacidade em ajustar a ingestão de MS em função da energia do alimento (Maertens, 1992).

Comparando as duas fontes de gordura, independentemente dos níveis utilizados, constata-se que o tipo de gordura não afetou significativamente nenhum dos parâmetros, exceto o peso do intestino, que foi maior $(\mathrm{P}<0,05)$ quando se utilizou a gordura animal.

\section{Conclusões}

A inclusão de 6,0\% de gordura vegetal ou animal em dietas para coelhos em crescimento ocasiona aumento do CDEE, reduz o consumo médio diário de ração e os pesos de fígado e coração, mas não influencia o peso final, o ganho de peso diário, a conversão alimentar e os pesos de carcaça, pele, rins e intestino dos animais.

A inclusão de $3 \%$ de OS em dietas para coelhos em crescimento melhora o CDFDN e o mesmo nível de GA proporciona maiores CCEE.

\section{Literatura Citada}

ASSOCIATION OF OFFICIAL ANALYTICAL CHEMISTS - AOAC. Official methods of analysis. 15.ed. Virginia: 1990. 1117p.

CARABAÑO, R.; FRAGA, M.J.; DE BLAS, J.C. Effect of protein source in fibrous diets on performance and digestive parameters of fattening rabbits. Journal of Applied Rabbit Research, v.12, n.3, p.201-204, 1989.

CERVERA, C.; BLAS E.; FERNANDEZ - CARMONA, J. Growth of rabbits under different environmental temperatures using high fat diets. World Rabbit Science, v.5, p.71-75, 1997.

CHAABANE, K.; BERGAOUI, R.; BEN HAMMONDA, M. Utilisation de differents types de grignons d'olive dans l'alimentation des lapereaux. World Rabbit Science, v.5, n.1, p.17-21, 1997.

CHEEKE, P.R. Alimentación y nutrición del conejo. Zaragoza: Acribia, 1995. 429p.

DALlE ZOTTE, A.; PARIGI-BINI, R.; XICCATO, G. et al. Effetto della dieta e della durata del pos-svezzamento sulla qualitá della carcassa e della carne di coniglio. In: CONGRESS OF ASPA, 12., 1996, Pisa. Proceedings... Pisa: 1997. p.383-384.

De BLAS, J.C.; MATEOS, G.G. Feed formulation. In: De BLAS, C., WISEMAN, J. (Eds.) The nutrition of the rabbit. Cambrigde: University Press - CAB International, 1998. p.241-253.

De BLAS, J.C.; GARCIA, J.; CARABAÑO, R. Role of fibre in rabbit diets. Annais Zootecnology, v.48, p.3-13, 1999.

De BLAS, J.C.; TABOADA, E.; MATEOS, G.G. Effect os substituition os starch for fiber and fat in isoenergetic diets on nutrient digestibility and reproductive performance of rabbits. Journal of Animal Science, v.73, p.1131-1137, 1995.

DE BLAS, J. C.; VILLAMIDE, M. J.; CARABAÑO, R. Nutritive value of cereal by-products for rabbits. Journal of Applied Rabbit Research, v.12, n.3, p.148-151, 1989.

EUROPEAN GROUP ON RABBIT NUTRITION - EGRAN. Harmonization in rabbit nutrition research: recommendations to analyse some basic chemical components of feeds and faeces. In: WORKSHOP OF EGRAM, 1999, Madrid. Proceedings... Madrid: 1999. 10p.

FALCÃO e CUNHA, L.; GARCIA, P.; FREIRE, J.P.B. Utilização de gorduras - óleo de soja e sebo - no regime alimentar do coelho em crescimento: resultados zootécnicos e digestibilidade. Revista Portuguesa de Zootecnia, v.2, n.1, p.87-98, 2000.

FALCÃO e CUNHA, L.; FERREIRA, P.; FREIRE, J.P. Étude de l'effet de l'interaction fibres $\times$ lipides dans l'alimentation du lapin: croissence, digestibilité et paramètres fermentaires. In: JOURNÈES DE LA RECHERCHE CUNICOLE, 7., 1998, Lyon. Proceedings... Lyon, 1998. p.383-384.

FALCÃO e CUNHA, L.; BENGALA-FREIRE, J.P.; GONÇALVES, A. Effect of fat level and fiber nature on performance, digestibility, nitrogen balance and digestive organs in growing rabbits. In: WORLD RABBIT CONGRESS, 6., 1996, Tolouse. Proceedings... Tolouse: AFC - INRA, 1996. v.1, p.157-164.

FERNANDEZ, C.; COBOS, A.; FRAGA, M. J. The effect of fat inclusion on diet digestibility in growing rabbits. Journal Animal Science, v.72, p.1508-1515, 1994.

FERREIRA, W.M. Efecto de la sustituición parcial del heno de alfafa por el orujo de uva o la pulpa de remolacha sobre utilización de la dieta y los rendimientos productivos en conejos en crecimiento. Madri: Universidad Politecnica de Madri, 1990. 251p. Tese (Doutorado) - Universidad Politecnica de Madri, 1990.

FRAGA, M.J.; PÉREZ DE AYALA, P.; CARABAÑO, R. et. al. Effect of type of fiber on the rate of passage and on the contribution of soft feces to nutrient intake of finishing rabbits. Journal of Animal Science, v.69, n.4, p.1566-1574, 1991.

FERNANDEZ, C.; FRAGA, M.J. The effect of dietary fat inclusion on growth, carcass characteristics and chemical composition of rabbits. Journal of Animal Science, v.74, n.1, p.20882094, 1996.

FERNÁNDEZ-CARMONA, J.; PASCUAL, J.J.; CERVERA, C. The use of fat in rabbit diets. In: WORLD RABBIT CONGRESS, 7. , 2000, Valência. Proceedings... Valência: AFC, 2000. v.1, p.29-56.

FERNANDEZ-CARMONA, J.; BERNAT, F.; CERVERA, C. et al. High lucerne diets for growing rabbits. World Rabbit Science, v.6, n.2, p.227-242, 1998.

FORTUN-LAMOTHE, L. Effects of dietary fat on reproductive performance of rabbit does: a review. World Rabbit Science, v.5, n.1, p.33-38, 1997.

GIDENNE, T.; LEBAS, F.F. Evolution circadienne du contenu digestif chez le lapin em croissance. Relation avec la caecotrophie. In: CONGRESSO MUNDIAL DE CUNICULTURA, 3., 1984, Roma. Anais... Roma: 1984. p.494-501.

GOMES, A.V.C. Avaliação nutricional de diferentes fontes de fibra em coelhos. Belo Horizonte: Universidade Federal de Minas Gerais, 1996. 129p. Tese (Doutorado) - Universidade Federal de Minas Gerais, 1996.

LEBAS, F. Nutrient requeriments of rabbits. Cuniculture Science, v.5, n.2, p. $128,1989$. 
LOPES, D.C.; ROSTAGNO, H.S.; FREITAS, R.T.F. Valores de energia digestível de alimentos e digestibilidade dos nutrientes de rações com diferentes níveis de energia para coelhos em crescimento. Revista Brasileira de Zootecnia, v.26, n.6, p.1147-1152, 1997.

MAERTENS, L. Rabbit nutrition and feeding - A review of some recent developments. Journal Apply Rabbit Research, v.15, n.1, p. 889-915, 1992.

MAERTENS, L. Fats in rabbit nutrition: a review. World Rabbit Science, v.6, n.3 e 4, p.341-348, 1998.

MANZANO, A.; WANDERLEY, R.C.; ESTEVES, S.N. Óleo de soja e gordura animal na alimentação de equinos. Revista Brasileira de Zootecnia, v.24, n.5, p.788-799, 1995.

MORETTI, A.M. Avaliação nutricional de diferentes fontes de óleo vegetal em dietas de coelhos em crescimento. Maringá: Universidade Estadual de Maringá, 2002.61p. Dissertação (Mestrado em Zootecnia) - Universidade Estadual de Maringá, 2002.

PASCUAL, J.J.; TOLOSA, C.; CERVERA, C. et al. Effect of diet with different digestible energy content on the performance of rabbit does. Animal Feed Science and Technology, v.81, p.105-117, 1999.

PÉREZ, J.M.; FORTUN-LAMOTHE, L.; LEBAS, F. Comparative digestibility of nutrients in growing rabbits and breeding does. In: WORLD RABBIT CONGRESS, 6., 1996, Toulouse. Proceedings... Toulouse: 1996. v.1, p.267-270.

PÉREZ. J.M.; LEBAS, F.; GIDENNE, T. et al. European reference method for in vivo determination of diet digestibility in rabbits. World Rabbit Science, v.3, n.1, p.41-43, 1995.

RAIMONDI, R.; AUXILIA, M.T.; MASAERO, G. et al. Effect of added fat in the feed on meat production by rabbits. 1. Growth, feed intake and carcass yield. Annali dell'Istituto Sperimentale per la Zootecnia, v.7, n.2, p.217-235, 1974.
SANTIAGO, G.S. Suplementação enzimática a dietas com diferentes teores e fontes de proteína para coelhos em crescimento. Belo Horizonte: Universidade Federal de Minas Gerais, 2001. 96p. Tese (Doutorado em Zootecnia) - Universidade Federal de Minas Gerais, 2001.

SANTOMÁ, G.; DE BLAS, J.C.; CARABAÑO, R. et al. The effects of different fats and their inclusin level in diets for growing rabbits. Animal Production, v.45, p.291-300, 1987.

SILVA, D.J. Análise de alimentos (Métodos químicos e biológicos). Viçosa, MG: Universidade Federal de Viçosa, 1990. 165p.

STATISTICAL ANALYSIS SYSTEM - SAS. User's guide: statistics. Cary: 1996.

SCHNEIDER, J.M.; FLAT, R.J. Aparent digestibility from different animals. Journal of Animal Science, v.40, n.3, p.553-557. 1975.

XICCATO, G. Nutrition of lactating does. In: WORLD RABBIT CONGRESS, 6., 1996, Toulouse. Proceedings... Toulouse: 1996. p.29-46.

XICCATO, G.; COSSU, M.E.; TROCINO, A. et al. Influence du rapport amidon/fibre et de l'addition de graisse en post-sevrage sur la digestion, les performance zootechniques et la qualité bouchère du lapin. In: JOURNÉES DE LA RECHERCHE CUNiCOLE, 7., 1998, Lyon. Proceedings... Paris: ITAVI, 1998. p. 159-162.

XICCATO, G.; PARIGI-BINI, R.; DALLE ZOTTE, A. et al. Effect of dietary energy level, addition of fat and physiological state on performance and energy balance of lactating and pregnant rabbit does. Journal of Animal Science, v.61, n.2, p.387$398,1995$. 